\title{
Play Your Process - Uma Método de Design de Jogos Digitais Baseados em Modelos de Processos de Negócio
}

\author{
Tadeu Moreira de Classe ${ }^{1}$, Sean Wolfgand Matsui Siqueira ${ }^{2}$, Renata Mendes de \\ Araujo $^{3,4}$, Geraldo Bonorino Xexéo 5
}

${ }^{1}$ Programa de Pós-Graduação em Informática (PPGI) - Universidade Federal do Estado do Rio de Janeiro (UNIRIO) - Rio de Janeiro - RS - Brasil

${ }^{2}$ Orientador - Programa de Pós-Graduação em Informática (PPGI) -Universidade Federal do Estado do Rio de Janeiro (UNIRIO) - Rio de Janeiro - RJ - Brasil

${ }^{3}$ Orientadora - Universidade Presbiteriana Mackenzie - São Paulo -SP - Brasil

${ }^{4}$ Programa de Pós-Graduação em Sistemas de Informação - EACH-USP - Brasil

${ }^{5}$ Co-Orientador - Programa de Engenharia de Sistemas e Computação (COPPE) Departamento de Ciência da Computação (IM) - Universidade Federal do Rio de Jeneiro

(UFRJ) - Rio de Janeiro, RJ, Brasil

\{tadeu.classe, sean\}@uniriotec.br, renata.araujo@mackenzie.br, xexeo@cos.edu.br

Resumo. Atualmente as organizações são desafiadas na tentativa de fazer com que seus clientes se aproximem e possam contribuir na inovação e melhoria de seus processos de negócio. Neste contexto, percebeu-se que estas melhorias passam pela compreensão dos processos pelos clientes tornando-os aptos a contribuir. Esta pesquisa explorou o design de jogos digitais como alternativa atrativa para que as pessoas possam compreender como um processo de negócio de prestação de serviço é executado. Através da Design Science Research Methodology (DSRM) o método Play Your Process (PYP) foi concebido, tendo como objetivo guiar o game designer na construção destes jogos. Com o método PYP foi possivel desenvolver e demonstrar os jogos digitais baseados em processos de negócio em diferentes contextos, sendo estes, avaliados com o público (cidadãos) quanto a sua qualidade e a ferramenta para promover a compreensão do processo de negócio (serviço). Assim, o método usa modelo de processos de negócio como base para a criação do jogo, e ao mesmo tempo o jogo digital busca representar o modelo de processo de negócio para a compreensão do jogador. O método PYP demonstrou ser útil para isso, ao fornecer suporte ao projeto de jogos digitais baseados em processos de negócio.

\section{Introdução}

Em ambientes cada vez mais conectados, mudanças na forma de criar e disseminar conhecimento acontecem rapidamente, uma vez que as Tecnologias de Informação e Comunicação (TICs) atuais permitem novas maneiras de obter e compartilhar informações entre indivíduos [Effing et al., 2011]. Destes ambientes surgem oportunidades para que as organizações possam melhorar e inovar seus processos de negócio, adotando tecnologias de gestão de processos de negócio (GPN), permitindo que seus clientes adquiram autonomia e satisfação juntos aos serviços prestados por elas, e permitindo que as pessoas busquem por si próprias soluções para seus problemas cotidianos [Pflanzl e Vossen, 2014].

Contudo, aproximar os clientes das organizações é um grande desafio, principalmente ao considerar o contexto de processos de prestação de serviços públicos [Araujo e Taher 2014]. Problemas como desconhecimento das regras de prestação de um serviço e características específicas das organizações contribuem com o distanciamento 
histórico entre estes atores, resultando, muitas vezes, na insatisfação do cidadão [Smith e Sawyer, 2008].

Compreender como um processo de prestação de serviços funciona pode ser uma tarefa bastante complexa para o cidadão [Alfaro et al., 2015]. Contudo, esta compreensão é um ponto crucial para que os clientes (acá cidadãos) possam se sentir confiantes em sugerir alternativas de melhorias e inovações, além de permitir aproximá-los das organizações [Engiel et al., 2014].

Neste contexto, esta pesquisa explora o potencial dos jogos digitais sérios como alternativa para promover a compreensão, por parte dos clientes externos de uma organização, sobre os processos de prestação dos serviços. Em particular, a pesquisa busca contribuir com as organizações de uma forma inovadora ao promover a participação social e cidadania por meio dos jogos.

$\mathrm{O}$ enfoque em jogos digitais deste trabalho é motivado, principalmente, devido às características de ensinar, permitir a compreensão e imergir os jogadores em resoluções de problemas em ambientes lúdicos existentes nos jogos sérios e educacionais. Há algum tempo e em diferentes áreas como educação, saúde, treinamento etc., estes jogos são usados como ferramentas para promoção de aprendizado, engajamento e imersão [Hamari et al., 2010].

Várias oportunidades surgem da aplicação destes jogos em ambientes organizacionais, mas na maior parte do tempo, elas estão relacionadas a promoção motivacional de funcionários. Ao contrário do contexto de promoção motivacional, estes jogos podem habilitar as pessoas que os joguem a compreender como um processo de negócio é executado, buscando entender sobre seu contexto, dificuldades, particularidades, valores, desafios e características [Classe e Araujo, 2016].

No design de jogos de entretenimento, questões de aprendizado são tratados em segundo plano, tendo foco primário o entretenimento do jogador [Siriaraya et al., 2018]. Enquanto no design de jogos sérios, o objetivo principal está na transferência de valores (objetos educacionais, treinamento etc.) para o jogador, ou seja, na transmissão de objetivos reais (daí o termo sério), e como o conhecimento adquirido nestes jogos pode influenciar vidas no mundo real [Michael e Chen, 2005].

Para construir jogos que possibilitem aos jogadores compreender processos de negócio é preciso pensar em como o design do jogo deve ser feito, de modo que o processo de negócio seja representado corretamente e, ao mesmo tempo, esteja balanceado aos elementos do jogo, para que este não se torne apenas um "simulador" [Classe et al., 2018c].

Diante disso, uma abordagem de sistematização do design de jogos digitais baseados em processos de negócio é uma oportunidade que deixará menos custosa, em termos de game design, a criação de jogos que permitam a compreensão de processos organizacionais pelos seus clientes. Portanto o problema principal da pesquisa pode ser descrito da seguinte forma: Como sistematizar o design de jogos digitais baseados em processos de negócio para que eles promovam a compreensão dos jogadores sobre estes processos.

Dado este problema, o objetivo principal deste trabalho foi desenvolver o método Play Your Process (PYP), um método de design de jogos digitais baseados em processos de negócio, como proposta de sistematização de design destes tipos de jogos, abordando os desafios de criação de jogos que transmitam o processo, possibilitando sua compreensão e reflexão pelos jogadores, sem que estes percam suas características lúdicas.

Com isso, os seguintes desafios foram abordados e trabalhos no método PYP: i) definição conceitual de elementos de design de jogos digitais baseados em processos de 
negócio garantindo seu alinhamento conceitual com elementos de modelos de processos de negócio organizacionais; ii) demonstração da viabilidade de construir jogos digitais baseados em processos de negócio em diferentes contextos, sobretudo na prestação de serviços públicos; iii) identificação de oportunidades de sistematização e automação do processo de design de jogos digitais baseados em processo de negócio, visando apoiar à produtividade do designer; iv) demonstração do potencial destes jogos para a compreensão de processos de negócio pelos seus jogadores; e, v) demonstração do potencial de sistematização de design destes jogos do ponto de vista de especialista em game design.

Este trabalho está organizado em 5 seções principais. A seção 1 apresentou a introdução com a motivação, justificativa, problema, objetivos e enfoque da pesquisa. A seção 2, introduz os arcabouços teóricos básicos e necessários para a compreensão do trabalho. A seção 3 traz, sucintamente, revisões de literatura e trabalhos relacionados realizados. A seção 4, apresenta o design da pesquisa, a metodologia usada e os ciclos de pesquisa realizadas durante a condução do trabalho. E a seção 5, contém as conclusões, limitações, oportunidades, contribuições científicas e tecnológicas e trabalhos futuros.

\section{Os Pilares da Pesquisa}

Esta seção apresenta os principais arcabouços conceituais das áreas de pesquisa de democracia digital, gestão de processos de negócio e jogos digitais, consideradas primordiais para a compreensão desta pesquisa. Como parte da seção, são apresentados trabalhos relacionados contendo interseções destas áreas.

\subsection{Democracia Digital}

Com a evolução tecnológica e o surgimento da Web, também surgiram novas formas de comunicação, de tal maneira que governos ao redor do mundo consideram estas mudanças como possibilidades inovadoras para realizar conversas e discussões públicas com os cidadãos [Yildiz, 2006]. Deste modo, surge o conceito de democracia digital (também conhecida na literatura como democracia eletrônica, ou ainda, e-democracia) [Vedel, 2006].

Segundo Silva [2005] democracia digital é: “o conjunto de discursos, teorizações e experimentações que empregam tecnologias de informação e comunicação (TICs) para mediar as relações políticas, tendo em vista as possibilidades de participação democrática nos sistemas políticos contemporâneos".

Neste contexto, Araujo e Taher [2014] propuseram um modelo que caracteriza níveis progressivos de participação cidadã (aproximação governo X cidadão), agindo em conjunto com as organizações por meio de tecnologias de interação social, sendo: a prestação de serviços; a coleta de opinião pública; a prestação de contas (accountability); a tomada de decisão deliberativa; e a tomada de decisão direta (codesign). Em seu nível mais básico está a prestação de serviços, a qual contempla a disponibilização de informações e prestação de serviços públicos, é um desafio ao se pensar em SI para apoiar a participação democrática [Araujo et al., 2012].

Ao propor que os jogos digitais baseados em processos de negócio são ferramentas úteis para que os cidadãos compreendam os processos de prestação de serviços públicos, entende-se que eles possam se aproximar das instituições prestadores dos serviços, desta maneira, esta pesquisa contribui para o primeiro nível de participação cidadã.

\subsection{Gestão de Processos de Negócio}

A disciplina, arte e ciência de analisar como um trabalho é realizado dentro das organizações para assegurar resultados positivos e oportunidades de melhorias nas atividades organizacionais é conhecida como Gestão de Processos de Negócio (GPN, ou 
em inglês, Business Process Management - BPM). A GPN é apoiada por etapas, as quais são conhecidas como ciclo de vida de GPN [Dumas et al., 2013]. Este ciclo de vida envolve as fases de: identificação do processo, descoberta do processo, análise do processo, redesenho do processo, implementação do processo e controle do processo.

A modelagem de processos de negócio é uma tarefa que está presente dentro do ciclo de vida da GPN possibilitando a sua análise. Ela consiste na formalização de um modelo do processo de negócio, atores, seus objetivos, métricas, fluxos, dados, integrações e relacionamentos entre áreas [Sobreira Neto, 2009]. Desta forma, os modelos de processo de negócio usam linguagens específicas, com finalidade de representação dos elementos do processo e como eles se relacionam, sendo úteis para a compreensão dos processos por especialistas [Aguilar-Saven, 2004].

Nesta pesquisa, conhecer os elementos de modelos de processo de negócio é uma tarefa primordial para o design de jogos digitais baseados em processos de negócio. É a partir deles que os designers de jogos baseiam os elementos que serão abordadas no jogo digital, de forma que este consiga ser uma representação fiel do processo, mesclando-os aos elementos lúdicos dos jogos.

\subsection{Jogos Digitais e Jogos Sérios}

De maneira geral, os jogos servem ao propósito de entretenimento, porém eles têm um grande potencial como ferramentas de suporte à socialização, educação e treinamento [Michael e Chen, 2005], e adicionalmente, seu sucesso aumenta com o crescimento exponencial que a indústria de jogos digitais teve nos últimos anos [Sakuda et al. 2018].

Petridis et al. [2015], através de uma revisão da literatura sobre jogos sérios, concluiu que eles têm um comprovado potencial para melhoria e eficácia dos programas de formação, o aumento da produtividade e até mesmo na resolução de problemas. Entretanto, para serem eficazes como métodos de treinamentos e compreensão de contextos por seus jogadores, os jogos sérios têm que atender não só os requisitos do treinamento, mas também as competências de domínio do jogo e os critérios de avaliação, fornecendo feedback para os jogadores [Rocha e Araujo, 2013].

Ao propor os jogos digitais baseados em processos de negócio, este trabalho abre oportunidade para uma categoria diferente de jogos sérios, os quais inclusive, necessitam de métodos, técnicas e ferramentas específicas para sua criação. Além de permitir pesquisas voltadas a criação e uso destes jogos para compreensão de processos de negócio pelos clientes, aqui usando como contexto os processos de serviços públicos.

\section{Trabalhos Relacionados}

Em Classe e Araujo [2015] e Classe et al. [2018a], os autores fizeram um mapeamento sistemático da literatura visando encontrar e analisar propostas de pesquisas que usassem, de alguma maneira, processos de negócio no design de jogos digitais. As buscas foram realizadas em bases científicas como IEEE Xplore, ACM, Science Direct, Web of Knowledge e Google Scholar, usando os termos (e suas variações, além de termos em inglês e português): democracia digital, gestão de processo de negócio e design de jogos digitais.

Nas buscas realizadas, poucos trabalhos foram encontrados, o que aponta a novidade deste tema de pesquisa. A maioria dos achados, como Bulander [2010], apontam para o uso de jogos para ensinar conceitos de modelagem de processos, não envolvendo métodos e técnicas de game desing para jogos voltados à compreensão de processos de negócio. Contudo, tais trabalhos serviram para demonstrar a existência de oportunidades 
inexploradas de pesquisa no campo de design de jogos, principalmente os jogos digitais baseados em processos de negócio.

Assim, o método PYP, proposto nesta pesquisa, difere dos trabalhos encontrados, ao propor o uso do modelo de processo de negócio como base do design do jogo, e não somente para organizar as etapas de um modelo. Inspirado pelo trabalho de Solís-Martines et al. [2015], que propõe uma ferramenta para o design de jogos digitais para treinamento em BPMN, buscou-se, também nesta pesquisa, criar um software que pudesse dar suporte ao método PYP, permitindo que os designers pudessem mapear os elementos do jogo de maneira automatizada, resultando na documentação do jogo.

\section{O Design da Pesquisa}

Esta seção descreve a metodologia de pesquisa baseada na Design Science Research (DSR). Uma descrição sucinta do design dos ciclos de investigação é apresentada, demonstrando como eles foram conduzidos no decorrer desta pesquisa. Cada ciclo foi baseado nas etapas descritas na Design Science Research Methodology (DSRM) [Peffers et $a l ., 2007]$.

\subsection{Design Science Research Methodology - DSRM}

A Design Science Research (DSR) é um paradigma epistemológico que operacionaliza a investigação fundamentada no paradigma da design science, que vem se popularizando na área de Sistemas de Informação (SI), devido às pesquisas que objetivam a produção de conhecimento que possa ser utilizado no desenvolvimento de soluções tecnológicas para diversos tipos de problemas [Hevner et al., 2004][Dresch et al., 2015].

Em DSR, um artefato é projetado para resolver algum tipo de problema dentro de um contexto, por meio de conjecturas e conhecimento sobre o mundo. Em contrapartida, o uso destes artefatos permite avaliar se as conjecturas que direcionaram o seu desenvolvimento parecem válidas. Desta maneira, o processo de criação de um artefato e a investigação de seu uso em um dado contexto se caracteriza como uma maneira para produzir conhecimento, o que faz com que o artefato seja um elemento central nas pesquisas desenvolvidas a partir da ótica da DSR [Dresch et al., 2015].

Segundo Peffers et al. [2007], existem diversificadas pesquisas que buscam trazer a design science para a comunidade de SI, apresentando métodos para a validade da DSR para suas pesquisas. Para conduzir as pesquisas em DSR é necessário um framework aceitável e comum que permita aos pesquisadores reconhecer e avaliar os resultados da pesquisa. Portanto, Peffers et al. [2007] propuseram a Design Science Research Methodology (DSRM).

Esta metodologia foi criada considerando os elementos mais aceitos e utilizados pelos pesquisadores em DSR, os quais, de acordo com Peffers et al. [2007] são: i) Identificação do Problema e Motivação: definição do problema de pesquisa e a sua justificativa; ii) Definição de Objetivos para a Solução: inferência sobre as conjecturas e objetivos para solução a partir da definição e conhecimento sobre o problema; iii) Design e Desenvolvimento: criação do artefato para tentar satisfazer o problema; iv) Demonstração: demonstração de que o artefato proposto pode satisfazer um ou mais instâncias do problema; v) Avaliações: observar e mediar o quão bem o artefato suporta a solução do problema, comparando seus objetivos com os resultados a partir do uso do artefato na demonstração. É comum na avaliação o uso de pesquisas qualitativas e/ou quantitativas, as quais buscam evidenciar os objetivos e conjecturas inferidas na etapa de definição dos objetivos; e, vi) Comunicação: comunicação sobre o problema e sua 
importância, o artefato e as inovações que ele trouxe, o rigor de seu design, e o conhecimento gerado.

Embora na DSRM existam etapas sob um processo sequencial, a sua execução pode acontecer de maneira iterativa, ou seja, é possível que após etapas de avaliação e comunicação, novos objetivos para a solução sejam definidos (insights), o que gera novas rodadas de desenvolvimento e consequentemente, as demais etapas da metodologia. Isso permite o desenvolvimento dos ciclos de pesquisas da DSR [Pefferset al., 2018].

\subsection{DSRM Descrita no Contexto Para Esta Pesquisa}

Tendo como cenário de investigação o contexto de processos de prestação de serviços pelas instituições públicas, e como permitir que estes serviços sejam melhorias e inovações, entende-se que há necessidade de os processos sobre como eles são prestados, sejam compreendidos pelos cidadãos. O desafio nesta área está em como promover soluções que permitam o engajamento e participação dos cidadãos neste processo de discussão e design de serviços [Govint, 2019].

O design de jogos sérios apresenta especificidades, como o foco na transmissão de objetivos para os jogadores, que não são contemplados por propostas clássicas de game design como as de Salen e Zimmerman [2003] e Schell [2009]. Cada jogo sério é criado para um contexto ou domínio, necessitando de métodos de design específicos que vão além das abordagens da engenharia de software e das propostas de design de jogos tradicionais [Rougas, 2016].

Para criar jogos digitais baseados em processos de negócio é necessário pensar em como o processo de negócio será traduzido para a linguagem do jogo, sem deixar que o jogo resultante seja apenas um simulador do processo, o que pode ser desinteressante ao jogador. Assim, a complexidade deste design está em balancear a fidelidade processo de negócio ao jogo, a diversão e a compreensão do jogador sobre o processo [Classe et al., 2019].

Durante as pesquisas realizadas neste trabalho não foram identificadas propostas que busquem especificamente a sistematização e design de jogos digitais baseados em processos de negócio. A inexistência de um método de design para jogos sérios baseados em processos de negócio limita as oportunidades do uso de jogos digitais como ferramenta para a compreensão e aproximação de atores e clientes de processos de negócio, e de melhoria e inovação de processos em organizações.

Visto isso, a DSRM foi usada como metodologia de pesquisa deste trabalho. Partindo de uma pesquisa centrada no problema: Como sistematizar o design de jogos digitais baseados em processos de negócio para que eles promovam a compreensão dos jogadores sobre os processos.

Para tratar este problema, é considerado como contexto o processo de prestação de serviços públicos, sendo proposto como artefato para tratar o problema o método Play Your Process (PYP) para o design de jogos digitais baseado em processos de negócio. No desenvolvimento do método, foram usadas como bases teóricas arcabouços conceituais e definições advindos da democracia digital, gestão de processos de negócio e jogos digitais, considerando, também, as bases técnicas de princípios de modelagem de processo de negócio e design de jogos digitais.

O artefato proposto visa validar as conjecturas teóricas de que: i) é possível sistematizar o design de jogos digitais baseados em processos de negócio; e ii) os jogos desenvolvidos por meio do método PYP possuem qualidade e conseguem transmitir as 
informações do processo de negócio, seu contexto e como o processo é executado para os jogadores; iii) o método permite o design de jogos baseados em processos de negócio por designers ou indivíduos sem muita afinidade com a área de modelagem de processos de negócio ou design de jogos digitais.

Como formas de avaliacão do artefato: i) demonstração do desenvolvimento de jogos digitais usando o método PYP; ii) avaliação do método PYP com designers de jogos tanto em ambiente acadêmico, quanto no mercado por meio da apresentação do método e entrevistas; e iii) estudos quasi-experimentais [Campbell e Stanley, 2015] e oficinas de avaliação dos jogos criados a partir do método PYP com designers de jogos, executores do processo e público alvo do processo que o jogo representa. Estes instrumentos de pesquisa foram usados, não para provar verdades sobre teorias e questões de design do artefato, mas para colocá-los em uso e obter insights para os próximos ciclos de pesquisa e melhorar o método de design de jogos digitais baseados em processos de negócio.

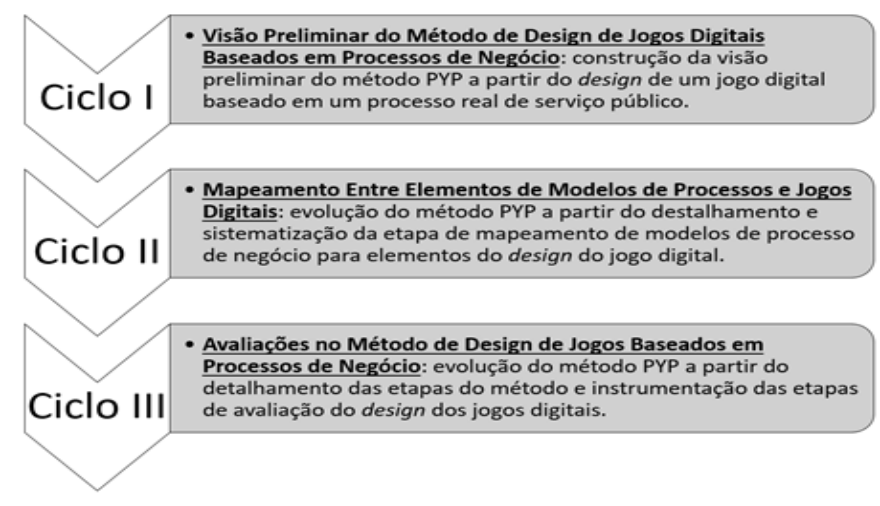

Figura 2. Ciclos de DSRM Propostos para a Pesquisa

\subsection{Ciclo I - Visão Preliminar do Método de Design de Jogos Digitais Baseados em Processos de Negócio}

Neste ciclo de pesquisa, o objetivo principal foi a construção da visão preliminar do método de design de jogos baseados em processos de negócio por meio do desenvolvimento de um jogo digital sobre um processo real (Figura 3). Este método preliminar recebeu o nome de Play Your Process (PYP), o qual é composto por etapas interativas, que usam modelos de processo de negócio com base para os elementos de design do jogo, buscando que estes, ao mesmo tempo sejam lúdicos ao jogador e não contradigam o processo de negócio. Neste ciclo a compreensão do processo de negócio (serviço público) e a qualidade do jogo, foram avaliados pelos jogadores de forma positiva, indicando que as etapas de design seguidas cumpriram o objetivo e os requisitos do PYP.

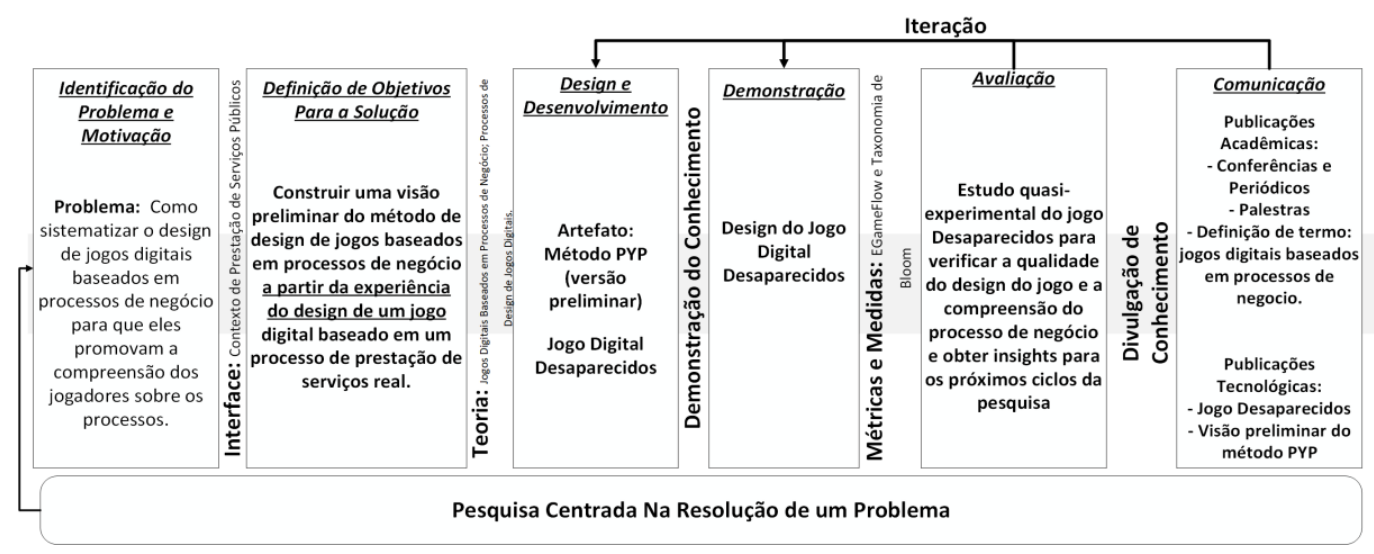

Figura 3. Design em DSRM do Ciclo I 
A partir de um estudo exploratório, tendo como contexto o processo de descoberta de pessoas desaparecidas aconteceu da Delegacia de Descoberta de Paradeiros (DDPA) da Polícia Civil do Rio de Janeiro, às etapas do método de design foram surgindo de forma Ad-hoc, a partir da experiência do design do jogo Desaparecidos. Isso deixou evidente na pesquisa, e reforçou ainda mais a ideia de que o design deste jogo precisaria do modelo de processo de negócio sobre o processo de negócio (Classe, 2017).

A partir do problema geral da pesquisa, neste ciclo o foco para a solução estava em aprender quais seriam as etapas de design para um jogo digital baseados em um processo de negócio. Portanto, uma visão preliminar do método PYP é o principal artefato do ciclo, tendo o jogo Desaparecidos como um artefato secundário, que demonstraria a viabilidade de design de jogos baseados em modelos de processos de negócio.

Por meio de brainstorms com o time de design e a análise do modelo do processo do serviço de descoberta de paradeiros, questões sobre como o jogo seria construído, quem seria o público alvo, localização do jogo e outras, foram discutidas, dando origem às etapas do método PYP na prática. Além disso, etapas importantes foram surgindo, como o mapeamento dos elementos do modelo de processo para os elementos do jogo.

Este exercício de mapeamento entre elementos pôde responder algumas questões a nível de projeto de jogo, por exemplo: o jogador poderia ser um executor no processo (alguma lane), pois, para entender as dificuldades e particularidades do processo entende-se que é preciso colocar o jogador (cidadão) em situações que ele não executaria normalmente. A narrativa do jogo deve considerar uma instância (exemplo) do processo de negócio; as mecânicas (regras em geral que permeia as atividades), devem obedecer às especificidades de cada uma das tarefas e condições do processo de negócio, por exemplo; O objetivo do jogo se alinha ao do processo de negócio. Além de outras associações de elementos realizadas (Figura 4).

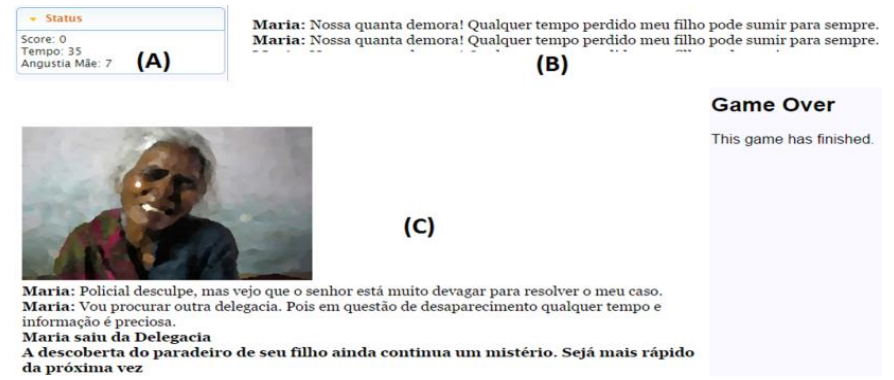

Figura 4. Elementos do Processo de Negócio Representados o Processo de Descoberta de Paradeiros no Jogo Desaparecidos

Com o jogo pronto, surgiu a necessidade de avaliar se o jogo cumpria o objetivo de fazer com que o jogador compreendesse o processo de negócio. A avaliação com os usuários do processo de negócio também é uma etapa necessária para o design de jogos digitais baseados em processo de negócio. É nesta etapa que se avalia se os jogadores conseguiram compreender o processo de negócio representado pelo jogo.

Visando avaliar o design do jogo digital "Desaparecidos" pelas etapas executadas no processo de design, um estudo quasi-experimental (classe de estudos de natureza empírica que faltam as características de controle completo e aleatoriedade na seleção dos grupos, presentes em métodos experimentais tradicionais [Campbell e Stanley, 2015]) foi realizado. Nesta avaliação foi usada a escala EGameFlow [Fu et al., 2009], concluindo como resultados da avaliação que este jogo, cumpria com o papel de fazer com que o jogador compreendesse o processo de negócio (pré e pós teste), além de que o jogo apresentava qualidade (percepção de qualidade do EGameFlow). 
Portanto, por meio de tentativas e erros no design do jogo Desaparecidos, foi possível identificar as etapas que constituíram a visão preliminar do método PYP (Figura $5)$.

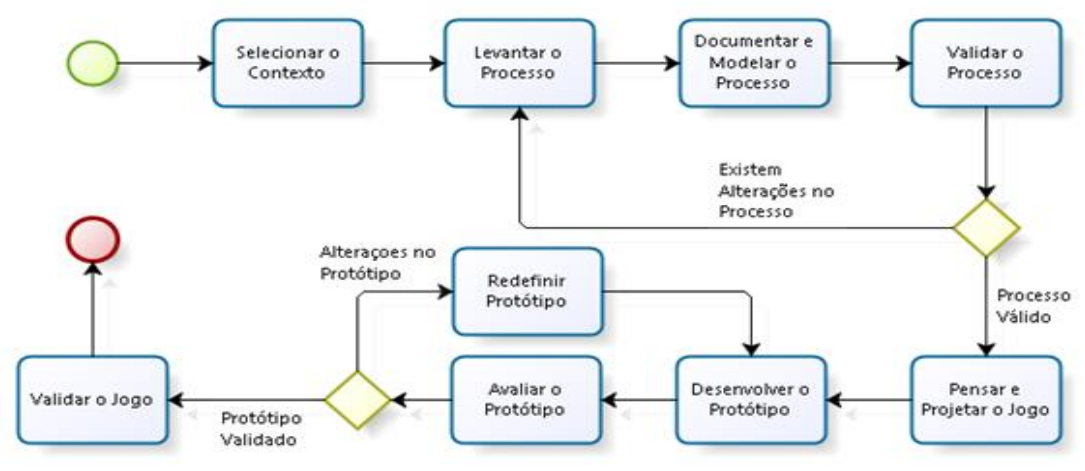

Figura 5. Versão Preliminar do Método PYP

Como uma das limitações deste ciclo a qual serviu de insight para o próximo, a associação de elementos (elementos de jogos e elementos do modelo de processo) foi conduzida de maneira ad-hoc, após uma análise manual de cada um dos elementos, a partir das experiências prévias sobre a modelagem de processos. Isso limita a realização do mapeamento de modo que somente designers de jogos que possuam habilidade e conhecimento sobre BPMN, conseguiram mapear os elementos do modelo do processo paro o jogo.

\subsection{Ciclo II - Mapeamento Entre Elementos de Modelos de Processos de Negócio e Jogos Digitais}

Este ciclo da DSRM, originado pelos insights obtidos no ciclo anterior, objetivou a evolução do método PYP, focando na proposta do mapeamento de elementos de modelos de processos de negócio para elementos de design de jogos digitais (Figura 6). Aqui, é apresentado um framework de mapeamento, no qual designers de jogos e analistas de processos, podem identificar elementos que irão compor o design do jogo digital.

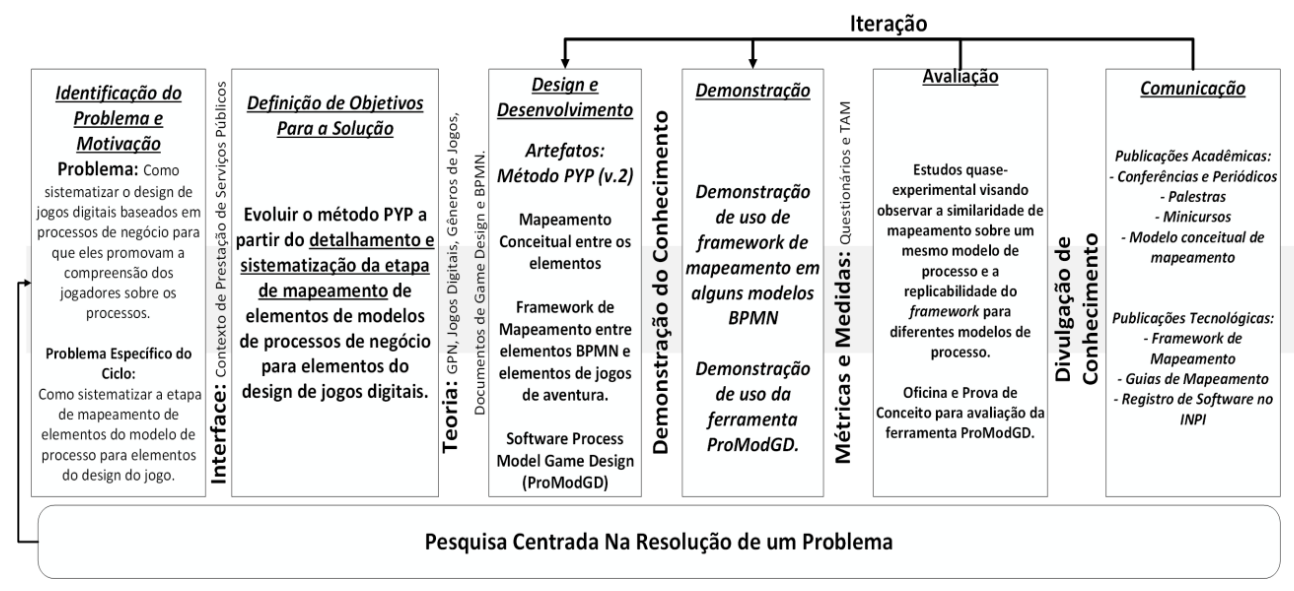

Figura 6. Design em DSRM do Ciclo II

Uma demonstração do mapeamento entre elementos foi realizada através de um estudo quasi-experimental [Classe et al., 2018b], tendo como objetivos verificar a viabilidade e utilidade da proposta de mapeamento por meio da similaridade (ou equivalência) dos elementos mapeamento usando o framework (Figura 7). A partir de um mesmo modelo de processo de negócio, foi analisado se os game designers conseguiam produzir um documento de mapeamento com elementos de design do jogo parecidos (ou equivalentes). 


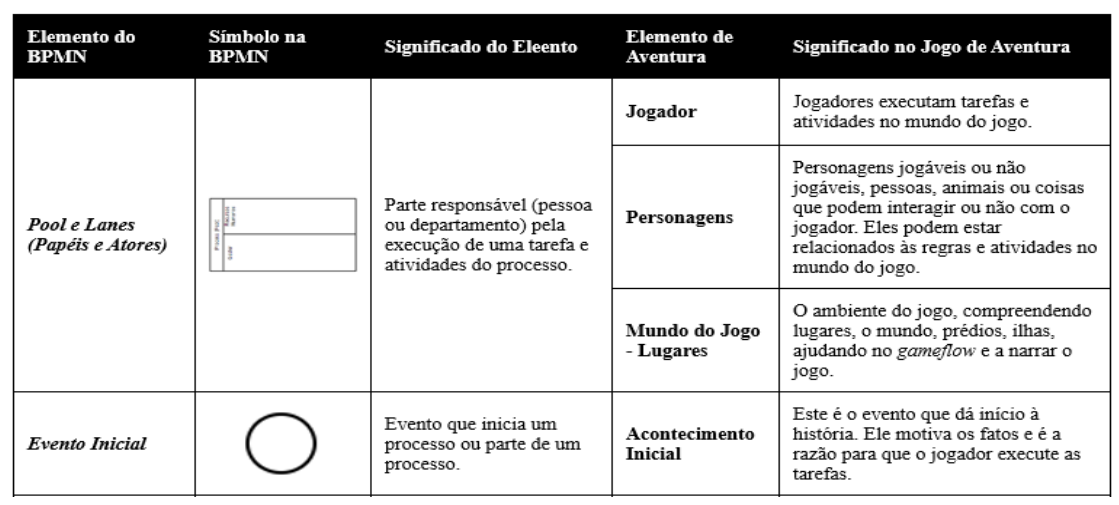

Figura 7. Recorte do Modelo Conceitual do Framework de Mapeamento

Ainda no estudo, buscou-se avaliar a replicabilidade do framework de mapeamento para modelos de processos diferentes. Foram mapeados pelos participantes do estudo 4 (solicitação de férias de uma empresa fictícia, processos reais de emissão de carteira de trabalho brasileira, alistamento militar e requisição de bolsas do PROUNI) modelos de processo de negócio em BPMN, e estes mapeamento foram computadas a similaridade dos elementos mapeados em cada uma delas (Tabela 1). Assim, o framework de mapeamento de elementos apresentou resultados satisfatórios, mostrando que em todos os 4 exemplos de modelos de processos, os designers conseguiram mapear de forma semelhante mais de $71 \%$ dos elementos dos processos em um mesmo modelo (pior caso). E como foram mapeados, também processos diferentes, é possível indicar que o framework pôde ser reprodutível a diferentes modelos de processo.

Tabela 1. Equivalência e Diferenças dos Mapeamentos

\begin{tabular}{|l|c|r|r|}
\hline Modelo Processo & Ver. & Equivalência (\%) & Diferenças (\%) \\
\hline Solicitação de Férias XPTO & v1 & 74,81 & 25,19 \\
\hline Emissão de Carteira de Trabalho (CTPS) & v2 & 71,35 & 28,65 \\
\hline Alistamento Militar & v3 & 90,44 & 9,56 \\
\hline Requisição de PROUNI & v3 & 82,94 & 17,06 \\
\hline Média & & $\mathbf{7 9 , 8 9}$ & $\mathbf{2 0 , 1 1}$ \\
\hline
\end{tabular}

Desta maneira, a partir do estudo, a necessidade de automatização desta tarefa (mapeamento de elementos) surgiu, devido ao mapeamento manual ser muito custoso e demorado, segundo os participantes. Visando automatizar o mapeamento, foi criado o software ProModGD (Process Model Game Design), onde partir de um modelo BPMN (Business Process Modeling and Notation) de entrada e a escolha do gênero de jogo, é gerado o mapeamento entre elementos a partir do framework e um Game Design Document (GDD) para apoiar a criação do jogo. Este software, também foi avaliada por usuários (game designers) a respeito de facilidade de uso e utilidade, sendo considerada viável pelos designers de jogos, evidenciando que ela consegue cumprir a proposta estipulada para este ciclo de pesquisa [Classe et al. 2018d].

Portanto, este ciclo teve como objetivo evoluir o método PYP por meio do detalhamento (framework) e sistematização (software) do mapeamento de elementos modelos de processo de negócio para elementos para o design do jogo digitais, partindo da conjectura que seria possível realizá-lo, e, inclusive fornecer a documentação inicial do documento de design do jogo (GDD). Ao estudar elementos de metamodelos de linguagens de modelagem de processos de negócio e a linguagem BPMN, junto aos elementos do gênero de jogos digital do gênero aventura, foi possível associá-los, por meio de seus significados, e compor um mapeamento conceitual que originou o framework de mapeamento criado neste ciclo. O que permite dizer que, ao voltar aos requisitos apresentados neste ciclo de pesquisa, que este framework cumpre com o especificado. 
Além disso, este ciclo permitiu conceituar e definir o gênero de jogos com propósito "jogos digitais baseados em processos de negócio" como: Jogos digitais com propósito que apresentam um processo de negócio de forma ludificada e permitem assim, aos jogadores, compreender e aprender seu funcionamento de forma divertida e engajante, considerando os elementos que compõem a definição deste processo (contexto, objetivo, atividades, atores, recursos, eventos, regras etc.) e desenvolver reflexões em relação à sua necessidade, sua prática, seus valores, seus desafios e limitações de execução. [Classe et al., 2019].

\subsection{Ciclo III - Avaliação do Método de Design de Jogos Digitais Baseados em Modelos de Processos de Negócio}

O terceiro ciclo de DSR tratou de evoluir o método PYP a partir do detalhamento de suas etapas, focando, principalmente, nas etapas de avaliação do design dos jogos digitais baseados em processos de negócio (Figura 8).

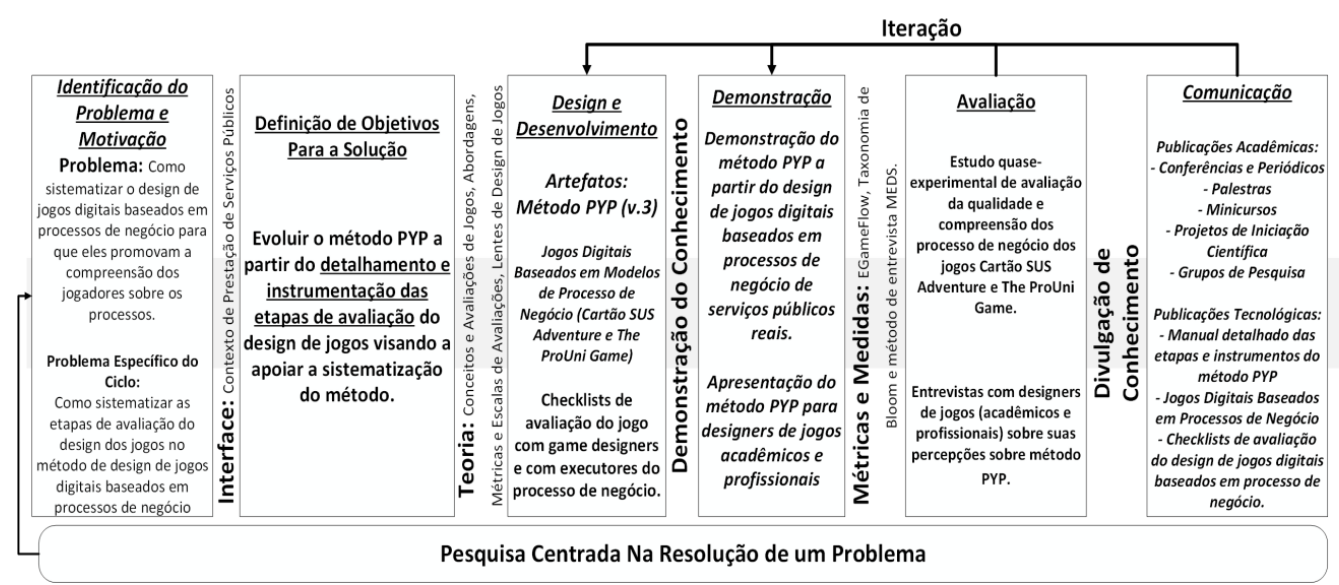

Figura 8. Design em DSRM do Ciclo III

Desde a versão preliminar (ciclo I), o método PYP prevê três etapas de avaliações diferentes, compreendendo a avaliação do jogo através do ponto de vista de designers, dos executores do processo e do público alvo. Desta forma, ao analisar o método preliminar, mantendo a evolução do mapeamento de elementos (ciclo II), algumas etapas foram reorganizadas e detalhadas [Classe et al., 2018c], removendo as que não faziam mais sentido (levantamento, documentação e modelagem de processo, já previstas pela GPN), gerando uma nova versão do método (Figura 9).

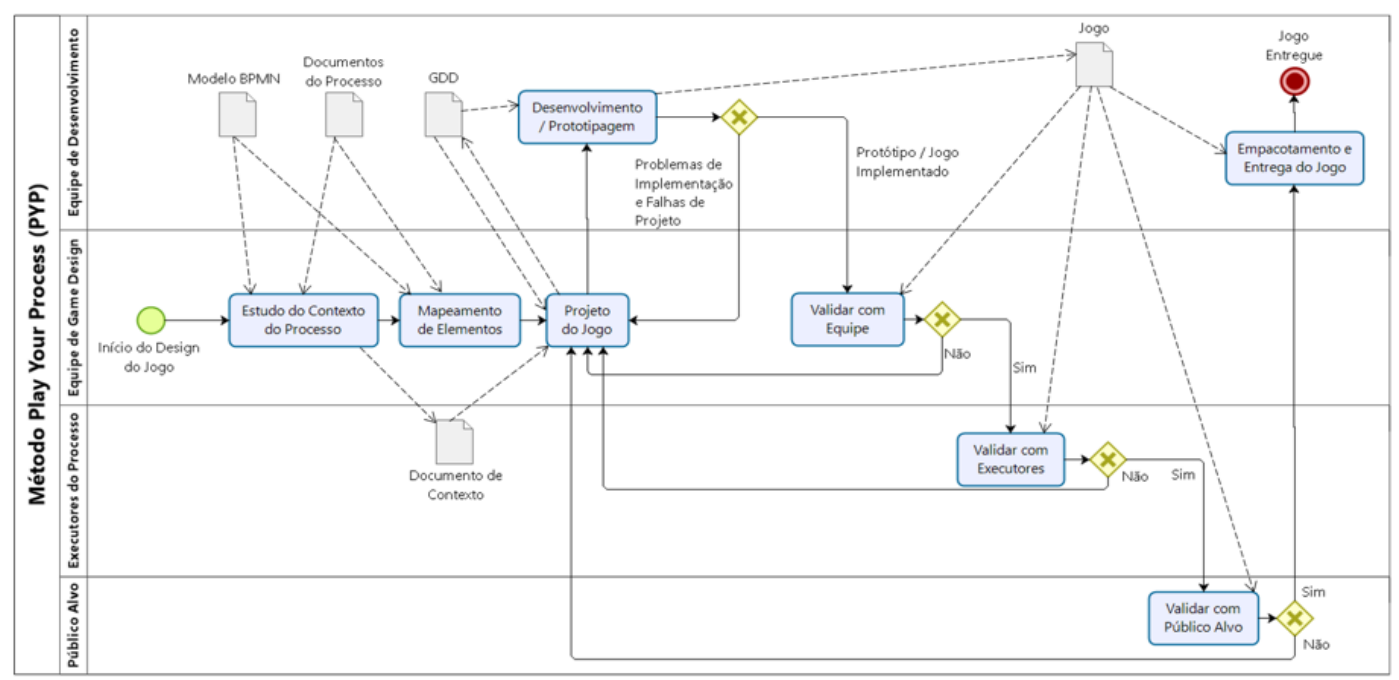

Figura 9. Versão do Play Your Process para o Ciclo III 
Deste modo, com a nova versão do método PYP, foram criados jogos digitais baseados em modelos de processos reais, demonstrando a viabilidade de seu uso. Adicionalmente, foi realizado um estudo qualitativo baseado em entrevistas com experts em design de jogos, tanto do meio acadêmico, quanto do mercado, buscando avaliar a proposta do método e suas etapas. Como conclusão, são apresentados os resultados e limitações do método de design.

Como demonstração do método e avaliação deste ciclo, foram desenvolvidos os jogos digitais Cartão SUS Adventure (processo de emissão do Cartão SUS) e o The ProUni Game (processo de solicitação de bolsas do ProUni). Ambos foram avaliados por jogadores (cidadãos) no contexto de prestação de serviços públicos que cada um representava. Assim como o Desaparecidos, todos os jogos conseguiram melhorar a compreensão do jogador (estudo pré e pós teste) sobre o processo de prestação do serviço, além de que o jogo fosse considerado de qualidade (percepção de qualidade pelo EGameFlow) (Figura 10).

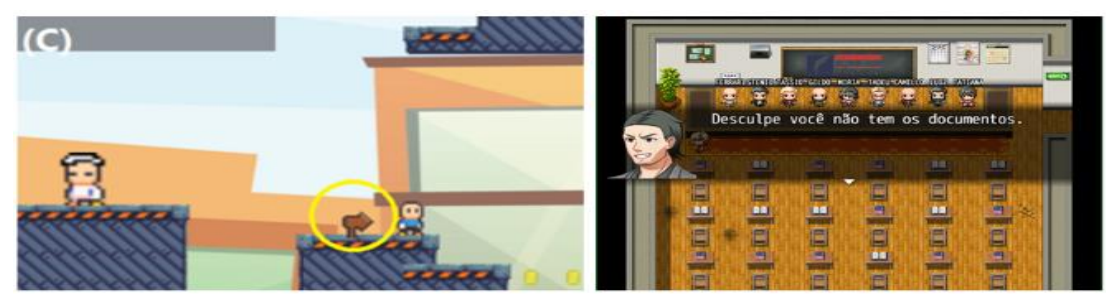

Figura 10. Exemplos de Cartão SUS Adventure e The ProUni Game

Além das demonstrações pode meio do design dos jogos, neste ciclo, o método PYP por completo foi avaliado por game designers através de entrevistas usando o método MEDS (Método de Extração do Discurso Subjacente). O MEDS é uma técnica de análise de dados qualitativos baseada na extração de informações a partir de dados coletados em entrevistas (Nicolaci-Da-Costa, 2007). A partir das entrevistas, de uma maneira geral os especialistas consideraram o método PYP muito útil para o design de jogos baseados em processos de negócio, e também, apresentando pontos fortes, fracos e sugestões de melhorias, que devem ser tratados em futuras versões do método PYP.

\section{Conclusões}

Neste trabalho foi realizada uma pesquisa tendo como contexto processos de prestação de serviços públicos, buscando a sua compreensão pelos cidadãos, por meio de jogos digitais, ou seja, jogos digitais baseados em processos de negócio. As conjecturas definidas no design da pesquisa foram baseadas em arcabouços conceituais e definições das áreas de democracia digital, gestão de processos de negócio e jogos digitais. Os resultados das avaliações de cada ciclo da pesquisa, permite retornar a elas para analisar se elas foram cumpridas de maneira satisfatória:

Sobre a conjectura de que é possível desenvolver jogos digitais de maneira sistemática, auxiliando que as organizações consigam transmitir seus processos de forma lúdica, acredita-se que ela tenha sido alcançado através da definição do método PYP, sendo a sistematização demonstrada por exemplos dos jogos digitais baseados em processos de negócio desenvolvidos nos ciclos da pesquisa, além de que os entrevistados perceberam que as etapas do método estão bem definidas e contribuem para o propósito de sistematização do design deste tipo de jogo sério.

Acredita-se que a conjectura de que os jogos digitais baseados em processos de negócio desenvolvidos pelo método PYP possuem qualidade e permitem que os jogadores compreendam o processo de negócio representados por eles também foi atingida, pois foi possível avaliar os jogos tanto no primeiro, quanto no terceiro ciclo e em suas avaliações os processos foram compreendidos pelos jogadores. 
A conjectura de que o método PYP permite pessoas com pouca habilidade com modelos de processos de negócio ou no design de jogos digitais consigam desenvolver um jogo baseado em processo de negócio também foi evidenciada a partir da demonstração dos designs dos jogos desenvolvidos no ciclo de pesquisa. A partir do mapeamento de elementos de modelos de processo de negócio para elementos do gênero aventura, foi possível construir jogos com bases nos processos de negócio, seguindo as etapas do método PYP.

De maneira geral, retornando ao problema geral da pesquisa: Como sistematizar o design de jogos digitais baseados em processos de negócio para que eles promovam a compreensão dos jogadores sobre estes processos. Em resposta, uma possibilidade é por meio do método PYP. Desta maneira, acredita-se que esta pesquisa de doutorado tenha satisfeito as conjecturas propostas no design da pesquisa e cumprido os objetivos da pesquisa, apresentando uma solução metodológica (método PYP) para o design de jogos digitais baseados em processo de negócio, buscando a compreensão dos clientes do processo.

\subsection{Contribuições Científicas}

Como contribuição científica, a pesquisa contribui para as três áreas principais tidas como pilares deste trabalho. A principal contribuição está na área de jogos digitais, foi definido e formalizando o método PYP, além do conceito de jogos digitais baseados em processos de negócio. Após isso, a contribuição se concentra na área de GPN, na tarefa de modelagem de processos de negócio e design jogos sérios, a contribuição científica foi o detalhamento de um modelo conceitual de mapeamento entre elementos de BPMN e elementos de jogos de aventura E por fim, na área de democracia digital, foi demonstrado a possibilidade de design de jogos digitais baseados em processos de prestação de serviços públicos, e que a partir destes jogos digitais é possível que os clientes do processo (cidadãos) compreendam aspectos de sua execução, contribuindo com o problema de aproximação entre cidadãos e instituições públicas.

\subsection{Contribuições Tecnológicas}

Entende-se que todos os artefatos produzidos a partir da execução dos ciclos de pesquisa sejam contribuições tecnológicas. Estas contribuições são: criação e detalhamento do método PYP; desenvolvimento dos jogos digitais baseados em processos de negócio; criação do framework de mapeamento e do software ProModGD, e registro dos softwares no INPI.

\subsection{Limitações da Pesquisa}

Esta pesquisa abordou o mapeamento de elementos de processos BPMN para o gênero aventura, abrindo oportunidade para trabalhos futuros nesta linha. É necessário realizar estudos visando identificar outros elementos de gêneros de jogos, e com isso, desenvolver novos mapeamentos conceituais que servirão de base para a criação de outros frameworks e guias de mapeamento.

A aproximação entre cidadãos e instituições públicas foi trabalhado na pesquisa a partir da compreensão do processo de negócio. Entretanto, a proposta do método PYP não visou resolver questões como a interação destes atores no ambiente do jogo, a melhoria dos processos, o engajamento e participação social. Questões, que devem ser tratadas com outras pesquisas sobre o tema.

Uma questão importante a se pesquisar é sobre os valores do processo e como se reflete em um jogo digital baseado em processo de negócio. Um processo de negócio, além 
de valores institucionais, possui valores agregados, éticos, morais etc., que variam com a percepção de uso de produto ou serviço e satisfação de seus clientes, por exemplo.

Outra limitação está na avaliação do método PYP pelos experts em design de jogos digitais. Nas entrevistas, embora as avaliações tenham sido consideradas como positivas pelos experts, elas apenas retratam a visão ou intenção de uso pelos entrevistados, já que nenhum deles colocou em prática o método PYP.

\subsection{Trabalhos Futuros}

É necessário observar que esta pesquisa é um primeiro passo para a concretização de outras pesquisas sobre o design de jogos baseados em processos de negócio. Ela apresenta limitações e oportunidades dentro desta linha. Há muitos trabalhos que precisam ser realizados, tanto para avaliar melhor a proposta, quanto para evoluí-las.

Existem trabalhos em andamento originados desta pesquisa, como dissertações de mestrado envolvendo o estudo dos valores em jogos baseados em processos de negócio e da melhoria do framework de mapeamento, por exemplo. Além disso, a nível de graduação, existem trabalhos que parte do desenvolvimento de outros jogos baseados em processos de negócio, o que permite estudar e exercitar mais sobre esta temática.

Criar maneiras específicas de avaliar estes jogos digitais baseados em processos de negócio também são necessárias, pois as atuais medidas para avaliar jogos educacionais ou sérios, não cobre especificidades (tarefas, valores, recursos etc.) dos jogos baseados em processos de negócio.

\section{Agradecimentos}

Renata Araujo é Bolsista de Produtividade em Desenvolvimento Tecnológico e Extensão Inovadora do $\mathrm{CNPq}$, processo $\mathrm{n}^{\mathbf{0}} 313210 / 2019-5$, e Sean Siqueira no processo $\mathrm{n}^{\mathbf{o}}$ 312039/2015-8. Este trabalho foi financiado em parte pelo Fundo Mackenzie de Pesquisa e pela FAPERJ.

\section{Referências}

Aguilar-Saven, R.S. (2004) "Business Process Modelling: Review And Framework". In: International Journal Of Production Economics, V.90(2), p. 129-149.

Alfaro, C.; Lavin, J.M.; Gomez, J.; Insua, D.R. (2015) "Epbpm: A Graphical Language Supporting Interoperability Of Participatory Process". In: International Conference OnEdemocracy\&Egovernment (Icedeg), p. 98-103.

Araujo, R.M., Cappelli, C., Diirr, B., Engiel, P., Tavares, R.L. (2012) "Democracia Eletrônica”. In: Sistemas Colaborativos, Org: Pimentel, M., Fuks, H., Rio De Janeiro, Elsevier.

Araujo, R.M.; Taher, Y. (2014) "Refining It Requirements For Government-Citizen CoParticipation Support In Public Service Design And Delivery". In: Conference For EDemocracy And Open Government, 2014, Krems. Cedem 2014. Krems: Donau Universität Krems, V. 1. p. 61-72.

Bulander, R. (2010) "A conceptual framework of serious games for higher education: Conceptual framework of the game INNOV8 to train students in business process modelling". In: Proceedings of the 2010 International Conference on e-Business (ICEB). p. 1-6.

Campbell. D.T.; Stanley, J.C. (2015) "Experimental And Quasi-Experimental Design For Research". Ravenio Books. 
Classe, T.; Araujo, R. (2016) “Jogos Digitais Para Participação Cidadã Em Processos De Prestação De Serviços Públicos". In: Workshop De Teses E Dissertações Do Simpósio Brasileiro De Sistemas De Informação.

Classe, T.; Araujo, R.M. (2015). Gamificação Para Participação Social Em Processos Públicos: Mapeamento Sistemático. In: Simpósio Brasileiro De Sistemas Colaborativos (Sbsc 2015), p. 130-137.

Classe, T.M.; Araujo, R.M.; Xexeo, G.B. (2018a) "Combining Business Process Models Into Digital Games Design: A Literature Review". In: Relatórios Técnicos Do Departamento De Informática Aplicada Da Unirio.

Classe, T.M; Araujo, R.M.; Xexéo, G.B. (2018b). "From Business Processes to Digital Games: A Mapping Proposal". In: Anais do XIV Simpósio Brasileiro de Sistemas de Informação (SBSI), p. 472-465.

Classe, T.M.; Araujo, R.M.; Xexeo, G.B.; Siqueira, S.W.M. (2018c) "PYP - Play Your Process: Um Método De Design De Jogos Digitais Baseados Em Processos De Negócio". In: Relatórios Técnicos Do Departamento De Informática Aplicada Da Unirio.

Classe, T.M.; Araujo, R.M.; Xexéo, G.B. (2018d) "Process Model Game Design: Uma Ferramenta para Apoio a Sistematização de Design de Jogos Digitais Baseados em Processos de Negócio". In: SBGames 2018, Foz do Iguaçu (PR), p. 233-242.

Classe, T.M.; Siqueira, S.W.M.; Araujo, R.M. (2017) "Um Estudo Sobre A Falta De Interesse Do Cidadão Em Se Tratando De Propostas Governamentais Apoiadas Por Mídias Sociais". In: Relatórios Técnicos Do Departamento De Informática Aplicada Da Unirio.

Classe, T. M.; Araujo, R. M.; Xexéo, G. B., Siqueira, S. (2019) "The Play Your Process Method for Business Process-Based Digital Game Design". In: International Journal of Serious Games, 6(1), p. 27-48.

Classe, T.M.; Araujo, R.M.; Xexeo, G.B.; (2019) "Jogos Digitais Baseados em Processos de Negócio". In: Simpósio Brasileiro de Jogos e Entretenimento Digital (SBGames) 2019 .

Dresch, A.; Lacerda, D.P.; Antunes, J.A.V. (2015) "Design Science Research: Método De Pesquisa Para Avanço Da Ciência E Tecnologia". Porto Alegre, Bookman.

Dumas, M.; La Rosa, M.: Mendling, J.; Reijers, H.A. (2013) "Fundamentals Of Business Process Management”. Berlin: Springer.

Effing, R.; Hillebgersberg, J. V.; Huibers, T. (2011) "Social Media And Political Participation: Are Facebook, Twitter And Youtube Democratizing Our Political Systems?" In: Epart 2011, p.25-35.

Engiel, P.; Araujo, R.; Cappelli, C. (2014) "Desigining Public Service Process Models For Understandability". In: Electronic Journal Of E-Government, V.12(1), p. 95-111.

Fu, F.; Su, R.; Yu, S. (2009) 'Egameflow: A Scale To Measure Learners' Enjoyment Of ELearning”. In Computer And Education, p. 101-112.

Govint. (2019) “Co-Production - How Does The Co-Production Star Toolkit Help You?”. In: Governance International.

Hamari, J., Koivisto, J., Sarsa, H. (2014) "Does Gamification Work? - A Literature Review Of Empirical Studies On Gamification". In: Hawaii International Conference On System Science, V.47, p. 3025-3034. 
Hevner, A.; March, S.; Park, J.; Ram, S. (2004) "Design Science In Information Systems Research". In: Mis Quarterly, V.28(1), p.75-105.

Michael, D., Chen, S. (2005) "Serious Games - Games That Educate, Train, And Inform". Thomson Course Technology Ptr, Boston.

Nicolaci-Da-Costa, A.M. (2007) "O Campo Da Pesquisa Qualitativa E O Método De Explicitação Do Discurso Subjacente (Meds)". In: Psicologia, Reflexão E Crítica, V.20(1), p.65-73.

Peffers, K.; Tuunanen, T.; Rothenberger M.A.; Chatterjee, S. (2007) "A Design Science Research Methodology For Information Systems Research". In: Journal Of Management Information Systems (Jmis), V.24(3), p. 45-77.

Petridis, P., Hadjicosta, K., Guang Shi, V., Dunwell, I., Baines, T., Bigdeli, A., Bustinza, O., Uren, V. (2015) "State Of The Art In Business Games". In: International Journal Of Serious Games, V.2(1).

Pflanzl, N.; Vossen G. (2014) "Challenges Of Social Business Process Management", In: 47th Hawaii International Conference On System Sciences, p. 3868-3877.

Rocha, R.V., Araújo, R.B. (2013) "Metodologia De Design De Jogos Sérios Para Treinamento: Ciclo De Vida De Criação, Desenvolvimento E Produção". In: Xii Simpósio Brasileiro De Jogos E Entretenimento Digital (Sbgames 2013), p. 1-10.

Rougas, B. (2016) "A Model-Driven Framework For Educational Game Design". In International Journal Of Serious Games, V3(3), p. 19-37.

Sakuda, L.O.; Fortim, I.; Azevedo, T.; Harris, J. (2018) “Análise Do Mercado Brasileiro De Jogos Digitais”. In: Sakuda, L. O.; Fortim, I. (Orgs.). Ii Censo Da Indústria Brasileira De Jogos Digitais. Ministério Da Cultura: Brasília.

Salen, K., Zimmerman, E. (2003) "Rules Of Play: Game Design Fundamentals". Cambridge, Mass.: Mit Press.

Sawyer, B., Smith, P. (2008) "Serious Games Taxonomy". In: Serious Games Summit At The Game Developers Conference.

Schell, J. (2009) “The Art Of Game Design A Book Of Lenses”. Burlington, Usa: Morgan Kaufmann Publishers \& Elsevier.

Silva, S. P. (2005) “Graus De Participação Democrática No Uso Da Internet Pelos Governos Das Capitais Brasileiras. In: Opinião pública, V. Xi(2), p. 450-468.

Siriaraya, P.; Visch, V.; Vermeeren, A.; Bas, M. (2018) "A Cookbook Method For Persuasive Game Design". In: International Journal Of Serious Games, 5(1).

Sobreira Neto, F. (2009) "Gerenciamento De Processos De Negócio - Bpm Segundo A Gestão Empresarial E A Tecnologia Da Informação: Uma Revisão Conceitual". In: Xxxiii Encontro Da Anpad, São Paulo.

Solís-Martínez, J.P. Espada, N. García-Menéndez, B. C. P.G-Bustelo, \& J. M. C. Lovelle, (2015) "Vgpm: Using Business Process Modeling For Videogame Modeling And Code Generation In MultiplePlatforms". In Computer Standards \& Interfaces, 42, p. 42-52.

Vedel, T. (2006) "The Idea Of Electronic Democracy: Origins, Visions And Questions". In: Parliamentary Affairs, V.59(2), p. 226-235.

Yildiz, M. (2006) "Decision-Making In E-Government Projects: The Case Of Turkey". In: Handbook Of Decision-Making, pp. 395-416. 